\title{
Treatment of patients with acute coronary syndrome: Recommendations for medical emergency teams: Focus on antiplatelet therapies. Updated experts' standpoint
}

Jacek Kubica ${ }^{1}$, Piotr Adamski ${ }^{1}$, Przemysław Paciorek ${ }^{1,2}$, Jerzy R. Ładny ${ }^{3}$, Zbigniew Kalarus ${ }^{4}$, Waldemar Banasiak ${ }^{5}$, Wacław Kochman ${ }^{6}$, Jarosław Gorący ${ }^{7}$, Beata Wożakowska-Kapłon ${ }^{8}$, Eliano Pio Navarese ${ }^{1}$, Andrzej Kleinrok ${ }^{9}$, Robert Gil ${ }^{10}$, Maciej Lesiak ${ }^{11}$, Jarosław Drożd $\dot{z}^{12}$, Aldona Kubica ${ }^{1}$, Krzysztof J. Filipiak ${ }^{13}$, Jarosław Kaźmierczak ${ }^{7}$, Aleksander Goch ${ }^{1}$, Stefan Grajek ${ }^{11}$, Andrzej Basiński ${ }^{6}$, Łukasz Szarpak ${ }^{13}$, Grzegorz Grześk ${ }^{1}$, Piotr Hoffman ${ }^{14}$, Wojciech Wojakowski ${ }^{15}$, Zbigniew Gąsior ${ }^{16}$, Sławomir Dobrzycki ${ }^{3}$, Jolanta M. Siller-Matula ${ }^{17}$, Adam Witkowski ${ }^{14}$, Wiktor Kuliczkowski ${ }^{18}$, Marcin Gruchała ${ }^{6}$, Dariusz Timler ${ }^{12}$, Grzegorz Opolski ${ }^{13}$,

Dariusz Dudek ${ }^{19}$, Jacek Legutko ${ }^{19}$, Marzenna Zielińska ${ }^{12}$, Jarosław Wójcik ${ }^{20}$

${ }^{1}$ Collegium Medicum, Nicolaus Copernicus University, Bydgoszcz, Poland; ${ }^{2}$ Regional Emergency Ambulance Service, Bydgoszcz, Poland; ${ }^{3}$ Medical University, Bialystok, Poland; ${ }^{4}$ Medical University of Silesia, Zabrze, Poland; ${ }^{5} 4^{\text {th }}$ Military Hospital, Wroclaw, Poland; ${ }^{6}$ Medical University of Gdansk, Poland; ${ }^{7}$ Pomeranian Medical University, Szczecin, Poland; ${ }^{8}$ Jan Kochanowski University, Kielce, Poland; ${ }^{9}$ Regional Hospital, Zamosc, Poland; ${ }^{10}$ Mossakowski Medical Research Centre, Polish Academy of Sciences, Warsaw,

Poland; ${ }^{11}$ Poznan University of Medical Science, Poznan, Poland; ${ }^{12}$ Medical University of Lodz, Poland;

${ }^{13}$ Medical University of Warsaw, Poland; ${ }^{14}$ Cardinal Stefan Wyszynski Institute of Cardiology, Warsaw, Poland; ${ }^{15}$ School of Medicine, Medical University of Silesia, Katowice, Poland; ${ }^{16}$ SHS Medical University of Silesia, Katowice, Poland; ${ }^{17}$ Medical University of Vienna, Austria; ${ }^{18}$ Wroclaw Medical University, Wroclaw, Poland;

${ }^{19}$ Collegium Medicum, Jagiellonian University, Krakow, Poland; ${ }^{20}$ Medical University of Lublin, Poland

\begin{abstract}
A group of Polish experts in cardiology and emergency medicine, encouraged by the European Society of Cardiology (ESC) guidelines, have recently published common recommendations for medical emergency teams regarding the pre-hospital management of patients with acute coronary syndrome. Due to the recent publication of the 2017 ESC guidelines for the management of acute myocardial infarction in patients presenting with ST-segment elevation and 2017 focused update on dual antiplatelet therapy in coronary artery disease the current panel of experts decided to update the previous standpoint. Moreover, new data coming from studies presented after the previous document was issued were also taken into consideration. (Cardiol J 2018; 25, 3: 291-300)
\end{abstract}

Key words: acute coronary syndrome, clopidogrel, emergency team, myocardial infarction, prasugrel, ticagrelor

Address for correspondence: Prof. Jacek Kubica, Department of Cardiology and Internal Medicine, Collegium Medicum, Nicolaus Copernicus University, ul. M. Skłodowskiej-Curie 9, 85-094, Bydgoszcz, Poland, tel: +48 52 5854023, fax: +4852 5854024, e-mail: jkubica@cm.umk.pl 


\section{Introduction}

A group of Polish experts in cardiology and emergency medicine, encouraged by the European Society of Cardiology (ESC) guidelines, have recently published common recommendations for medical emergency teams regarding the pre-hospital management of patients with acute coronary syndrome (ACS). These recommendations are also meant for the organization of regional networks designed to provide reperfusion therapy expeditiously and effectively [1]. Due to the recent publication of the 2017 ESC guidelines for the management of acute myocardial infarction (MI) in patients presenting with ST-segment elevation and the 2017 update focused on dual antiplatelet therapy (DAPT) in coronary artery disease, the current panel of experts decided to update the previous standpoint [1-3]. Moreover, new data coming from studies presented after the previous document was issued, were also taken into consideration.

In spite of the improvement in prognosis for patients with ACS, particularly with MI, which has been observed in recent years, this form of coronary artery disease is still associated with high risk of death. The total in-hospital mortality rate among patients with MI in Poland is about $11 \%$ (6\% for patients managed invasively vs. $18-24 \%$ for patients receiving conservative treatment), while the mortality rate in the first 12 months after MI is up to $19 \%$ [4]. It should be noted that, despite a major reduction in the in-hospital mortality rate, pre-hospital mortality remains relatively high.

Due to different management strategies applied in patients with ACS, the diagnosis is commonly classified as ST-segment elevation MI (STEMI) or non-ST-segment elevation ACS (NSTE-ACS), which includes non-ST-segment elevation MI (NSTEMI) and unstable angina (UA) [1] .

\section{Diagnosis and logistics of ACS patients}

According to the current guidelines, the ambulance system plays a critical role in the early management of ACS patients and is not only a mode of transportation, but also a system to enhance early diagnosis, triage, and treatment $[5,6]$. To improve quality of care and decrease adequate treatment delay, an early working diagnosis of ACS and risk stratification should be conducted as soon as possible. Presence of concordant ST-segment elevation (i.e. in leads with positive QRS deflections) appears to be one of the best indicators of ongoing MI with an occluded infarct artery [7]. In patients with a clinical suspicion of STEMI, reperfusion therapy needs to be initiated as soon as possible, thus direct transportation to centres with invasive cardiology facilities is indispensable [8]. Subjects with ongoing myocardial ischemia and left or right bundle branch block should be managed similar to STEMI patients, regardless of whether the bundle branch block has been previously known $[2,9]$. Other atypical electrocardiographic presentations that should prompt a primary percutaneous coronary intervention (PCI) strategy in patients with ongoing symptoms consistent with myocardial ischemia, are: ventricular paced rhythm (during right ventricular pacing, the electrocardiogram [ECG] shows left bundle branch block), isolated posterior MI (isolated ST depression $\geq 0.5 \mathrm{~mm}$ in leads V1-V3 and ST-segment elevation ( $\geq 0.5 \mathrm{~mm}$ ) in posterior chest wall leads V7-V9), ischemia due to left main coronary artery occlusion or multivessel disease (ST depression $\geq 1 \mathrm{~mm}$ in eight or more surface leads, coupled with ST-segment elevation in aVR and/or V1) [2].

In the absence of ST-segment elevation or atypical electrocardiographic presentations mentioned above, an immediate PCI strategy is indicated in patients with suspected ongoing ischemic symptoms suggestive of MI and at least one of the following criteria present (NSTE-ACS of very high risk) [10]:

- hemodynamic instability or cardiogenic shock;

- recurrent or ongoing chest pain refractory to medical treatment;

- life-threatening arrhythmias or cardiac arrest;

- mechanical complications of MI;

- acute heart failure;

- recurrent dynamic ST-segment or T-wave changes, particularly with intermittent ST-segment elevation.

The ECG monitoring should be applied immediately in all patients with initial diagnosis of ACS in order to detect life-threatening arrhythmias and allow prompt defibrillation, if indicated [2]. A strategy aimed to reduce treatment delay leading to mortality reduction in STEMI and very high risk NSTE-ACS patients should be applied. Therefore teleconsultation including transmission of patients' 12-lead ECG and clinical data to the destination centre should be performed within $10 \mathrm{~min}$ from the first medical contact $[1,2,11]$. This allows immediate activation of the interventional team and direct transportation of patients triaged for a primary PCI strategy to the catheterization laboratory, bypassing the emergency department $[1,2,11-16]$. 


\begin{tabular}{|l|c|c|c|c|c|c|}
\hline & $\begin{array}{c}\text { Previous } \\
\text { guidelines }\end{array}$ & $\begin{array}{c}\text { Class of } \\
\text { recommendation }\end{array}$ & $\begin{array}{c}\text { Level of } \\
\text { evidence }\end{array}$ & $\begin{array}{c}\text { Current } \\
\text { guidelines }\end{array}$ & $\begin{array}{c}\text { Class of } \\
\text { recommendation }\end{array}$ & $\begin{array}{c}\text { Level of } \\
\text { evidence }\end{array}$ \\
\hline STEMI & 2012 & $\mathrm{I}$ & $\mathrm{C}$ & 2017 & Ila & C \\
\hline NSTE-ACS & 2011 & $*$ & $*$ & 2015 & $*$ & $*$ \\
\hline
\end{tabular}

Figure 1. European Society of Cardiology recommendations for use of morphine in patients with acute coronary syndromes; NSTE-ACS - non-ST-segment elevation acute coronary syndrome; STEMI — ST-segment elevation myocardial infarction; *No official recommendation.

The efficient treatment of ACS patients requires appropriate ambulance equipment and staff competences. All medical emergency system ambulances should be equipped with ECG recorders, defibrillators, and at least one person trained in advanced life support. All ambulance personnel should be trained to recognize clinical symptoms of acute MI, record and transmit ECG, administer oxygen when appropriate, relieve pain, and provide basic life support $[2,17]$.

According to the available data, approximately $2 \%$ of all patients with MI undergo urgent coronary artery bypass grafting (CABG) during hospitalization due to ACS [4]. Identification of patients requiring $\mathrm{CABG}$ is based on the results of imaging of the coronary arteries (coronary angiography) and therefore is not possible in the pre-hospital period. However, the fact that some patients may require urgent cardiac surgery shortly after establishing the diagnosis of ACS by the medical emergency team should somehow affect and define the prehospital management strategy in these cases. Whenever possible, direct transport of the highest risk patients (STEMI and NSTE-ACS of very high risk) to centres with both invasive cardiology and cardiac surgery facilities should be considered. It should be stressed however, that preference for this category of hospitals must not cause delay of invasive diagnostics [1].

To ensure high quality of care in ACS patients, a working diagnosis, pivotal statements, decisions, medications, and time-points should be registered and monitored. If projected target times are not met, then local interventions are needed to improve performance of the system [2].

\section{Chest pain treatment}

Morphine is the most commonly used analgesic in patients with ACS at the pre-hospital stage, particularly in those with MI, due to its potential positive effect on the pathophysiology of ACS, high efficacy in symptomatic management of chest pain, wide availability, and long-term experience of clinical use $[1,2,18]$. However, the use of morphine quite commonly produces adverse effects, such as bradycardia, arterial hypotension, and impairment of the intestinal propulsive function, and also sometimes a suppression of respiratory function $[1,19]$. Moreover, morphine use is associated with slower uptake, delayed onset of action, and diminished effects of oral antiplatelet agents (i.e. clopidogrel, ticagrelor, and prasugrel) [2,20-23]. There are no randomized clinical studies evaluating the safety of morphine in patients with ACS, and the data from registries are equivocal [24-26]. Moreover, results of numerous clinical trials indicate a possible negative effect of morphine on the extent of MI and mortality rate [25, 27]. As there is no effective alternative to morphine in chest pain management in patients with ACS, this medicine reappeared in the latest ESC guidelines concerning the management of STEMI, but with diminished class of recommendations (IIa) when compared with the previous edition (I) [2, 28]. The most recent guidelines concerning the management of NSTE-ACS provide no official recommendation for the use of morphine in this group of patients. However, the authors of these guidelines have stated that the administration of opioids is reasonable in NSTE-ACS patients with sustained severe chest pain who are waiting for urgent coronary angiography [10]. It should be noted that all these recommendations are solely based on the expert opinions (level of evidence - C) (Fig. 1).

Considering the available knowledge, routine withdrawal from morphine use in ACS patients should not be recommended. It seems reasonable to reserve morphine administration only for those patients who report severe chest pain or present with signs of acute heart failure (e.g. resting dyspnoea). Moreover, use of the minimal effective dose with a view to limit the adverse effects of morphine should be applied [1]. Also, when morphine is used, the administration of oral antiplatelet drugs in a crushed form may be 
Table 1. Comparison of P2Y12 receptor inhibitors recommended by the European Society of Cardiology.

\begin{tabular}{|c|c|c|c|c|}
\hline & Clopidogrel & Prasugrel & Ticagrelor & Cangrelor \\
\hline Chemical class & Thienopyridine & Thienopyridine & $\begin{array}{l}\text { Cyclopentyl- } \\
\text { triazolo-pyrimidine }\end{array}$ & $\begin{array}{l}\text { Adenosine } \\
\text { triphosphate } \\
\text { analogue }\end{array}$ \\
\hline Administration route & Oral & Oral & Oral & Intravenous \\
\hline \multicolumn{5}{|l|}{ Standard dosing: } \\
\hline Loading dose & 300 or $600 \mathrm{mg}$ & $60 \mathrm{mg}$ & $180 \mathrm{mg}$ & $30 \mu \mathrm{g} / \mathrm{kg}$ bolus \\
\hline Maintenance dose & $\begin{array}{c}1 \times 75 \mathrm{mg} \\
\text { or } 1 \times 150 \mathrm{mg}\end{array}$ & $\begin{array}{c}1 \times 10 \mathrm{mg} \\
\text { or } 1 \times 5 \mathrm{mg}\end{array}$ & $2 \times 90 \mathrm{mg}$ & $\begin{array}{c}4 \mu \mathrm{g} / \mathrm{kg} / \mathrm{min} \\
\text { infusion }\end{array}$ \\
\hline Prodrug & Yes & Yes & No & No \\
\hline P2Y12 receptor binding & Irreversible & Irreversible & Reversible & Reversible \\
\hline Onset of antiplatelet effect & $2-6 \mathrm{h \#}$ & $30 \mathrm{~min} \#$ & $30 \mathrm{~min} \#$ & $2 \min$ \\
\hline Offset of antiplatelet effect & $3-10$ days & 5-10 days & $3-4$ days & $1-2 \mathrm{~h}$ \\
\hline $\begin{array}{l}\text { Recommended withdrawal } \\
\text { before surgery }\end{array}$ & 5 days & 7 days & 5 days & 1 hour \\
\hline
\end{tabular}

\#Data from healthy volunteers and patients with stable coronary disease. In patients with acute coronary syndromes the onset of action is probably delayed.

considered. It was demonstrated that crushing the tablets accelerates their absorption from the gastrointestinal tract and shortens the time to onset of action [29-32]. Moreover, recently performed research revealed that concomitant intravenous injection of metoclopramide improves ticagrelor absorption despite the use of morphine (NCT02939235). Thus, concomitant intravenous injection of metoclopramide should be considered in patients with ACS treated with morphine. Additionally, a mild tranquillizer (e.g. benzodiazepine) should be considered in very anxious patients [2]. Due to potential harmful effect of oxygen in uncomplicated MI patients it should be used only in hypoxic patients with arterial oxygen saturation $\left(\mathrm{SaO}_{2}\right)<90 \%[2,33]$.

\section{Antiplatelet treatment in ACS patients}

Activation and aggregation of platelets play a key role in the pathophysiology of ACS, including MI [34, 35]. Restriction of excessive platelet activation and inhibition of platelet aggregation with DAPT, including acetylsalicylic acid (ASA) and one of the P2Y12 receptor inhibitors, is a standard of care in patients with ACS $[2,3,10,36]$.

\section{ASA therapy in patients with ACS}

Acetylsalicylic acid is an irreversible inhibitor of platelet cyclooxygenase isoenzyme type 1 (COX-1). According to the current guidelines, administration of an oral, rapidly absorbed ASA formulation in a loading dose of $150-300 \mathrm{mg}$ is recommended in all ACS patients with no contraindications and no history of prior chronic use of ASA. When oral intake is not possible, ASA can be administered intravenously in the dose of 75-150 mg, however the i.v. formulation of ASA is not available in Poland. In STEMI and very high risk NSTE-ACS patients treatment should be applied as early as possible, i.e. upon the first medical contact. Then, all patients should receive chronic therapy with ASA 75-100 mg q.d. $[2,3,10]$.

\section{Platelet P2Y12 receptor inhibitors}

The current recommendations concerning the treatment of patients with ACS emphasize the need to use DAPT for 12 months following ACS, unless contraindicated due to an excessive risk of bleeding - class of recommendation I, level of evidence A. This recommendation is valid for patients both with STEMI and NSTE-ACS [2, 10, 36, 37].

Currently, oral platelet P2Y12 inhibitors available in Poland are: clopidogrel, prasugrel, and ticagrelor. A registered, but still unavailable medication of this group is cangrelor - a compound designed for intravenous use only. Clopidogrel and prasugrel are pro-drugs and require activation in the liver into active metabolites irreversibly blocking the $\mathrm{P} 2 \mathrm{Y} 12$ receptor, whereas ticagrelor and cangrelor are active drugs, which directly and reversibly block this receptor (Table 1) [36]. The guidelines preferentially recommend the newer P2Y12 inhibitors (prasugrel and ticagrelor) due to their faster, 
more potent, and more uniform anti-aggregation effect translating into better clinical outcomes as compared with clopidogrel [1, 2, 10, 38-42].

When starting the treatment with P2Y12 inhibitors one should always be aware of contraindications for these drugs. Prasugrel is contraindicated in patients with a history of intracranial hemorrhage, ischemic cerebral stroke or transient ischemic attacks, or with active bleeding. Prasugrel is generally not recommended for patients above 75 years of age or with body weight below $60 \mathrm{~kg}$. Also, ticagrelor is contraindicated in patients with a history of intracranial hemorrhage or with an active bleeding. Moreover, both prasugrel and ticagrelor are not recommended for use in dialysis patients or in those requiring chronic oral anticoagulation. When neither of these agents is available or if they are contraindicated, clopidogrel should be administered instead [43].

Many patients presenting with ACS require long-term oral anticoagulation. The concomitant use of DAPT and oral anticoagulation increases the risk of bleeding complications 2 - to 3 -fold when compared to anticoagulation alone [44-47]. Clopidogrel is the only P2Y12 inhibitor to be used in combination with oral anticoagulants (acenocoumarol, apixaban, dabigatran, rivaroxaban, or warfarin) [2]. Use of ticagrelor or prasugrel as a part of triple therapy is not recommended class of recommendation III, level of evidence $\mathrm{C}$ $[2,3,10]$.

Based on theoretical evidence derived from pharmacokinetic and pharmacodynamic properties as well as on the results of clinical studies, cangrelor appears to be the optimal P2Y12 inhibitor for ACS patients requiring urgent invasive treatment $[48,49]$. Due to its rapid onset of action this compound may be considered in patients not pretreated with oral $\mathrm{P} 2 \mathrm{Y} 12$ receptor inhibitors at the time of PCI or in those who are considered unable to absorb oral agents, particularly in unconscious patients, patients with post-cardiac arrest syndrome, or patients treated with mild therapeutic hypothermia, when gastrointestinal absorption of medications is impaired [2, 50, 51]. Unfortunately, cangrelor is not currently available in Poland.

\section{Platelet P2Y12 receptor inhibitors in the treatment of patients with STEMI}

ST-segment elevation MI is most commonly caused by total occlusion of a coronary artery, which results in progressive necrosis of myocardial cells. This implies the necessity to restore patency of the occluded artery as soon as possible. The preferred method of coronary revascularization is PCI [2, 36]. In STEMI patients potent P2Y12 inhibitor (prasugrel or ticagrelor), or clopidogrel if these are not available or are contraindicated, is recommended before or at latest at the time of PCI, and should be maintained for 12 months, unless contraindications such as excessive risk of bleeding exist - class of recommendation I, level of evidence A $[2,52,53]$. The available data suggest that, as prompt as possible, administration of P2Y12 receptor inhibitor may be preferable to achieve early efficacy [2]. Thus, a P2Y12 receptor inhibitor should be administered at the first contact with the healthcare system [36]. Although this approach appears to be justified, currently there are no randomized clinical trials demonstrating clear clinical benefits of this treatment strategy [1]. Administration of oral P2Y12 inhibitors in pre-hospital management of patients with STEMI is considered to be safe [54]. In patients with STEMI prasugrel (loading dose of $60 \mathrm{mg}$ ) and ticagrelor (loading dose of $180 \mathrm{mg}$ ) are both equally recommended [1-3, 36]. As mentioned earlier, when prasugrel or ticagrelor are unavailable or contraindicated, a loading dose of clopidogrel $(600 \mathrm{mg}$ ) should be administered $[2,36]$. In patients who have already received a loading dose of clopidogrel the antiplatelet therapy should be switched to ticagrelor at a loading dose of $180 \mathrm{mg}$ (class of recommendation I, level of evidence B), which is not recommended for prasugrel [53].

Prasugrel is also not indicated in patients with ACS in whom coronary anatomy is not known and an indication for PCI is not clearly established, with the exception of STEMI patients scheduled to undergo immediate coronary catheterization and PCI, if clinically indicated [3].

\section{Platelet P2Y12 receptor inhibitors}

in the treatment of patients with NSTE-ACS

While early initiation of antiplatelet therapy and urgent coronary reperfusion are recommended for patients with STEMI, in patients with NSTE-ACS the indications and recommended timeframes for diagnostics and potential invasive treatment depend primarily on the risk stratification [1]. The immediate interventional approach (within $2 \mathrm{~h}$ ) is indicated in very high risk NSTE-ACS patients. Similar to STEMI, DAPT, including ASA and one of the P2Y12 inhibitors, is also recommended in patients with NSTE-ACS, unless contraindicated, e.g. due to excessive bleeding risk [10]. The guidelines concerning the treatment of NSTE-ACS contain information that therapy with P2Y12 inhibitors should be instituted immediately after establish- 
ing the diagnosis of NSTE-ACS, regardless of the management strategy. In this group of patients the preferred P2Y12 inhibitors are prasugrel and ticagrelor, with equal recommendations - class of recommendation I, level of evidence B [10]. However, in patients with NSTE-ACS prasugrel should not be given prior to coronary angiography or when qualified for conservative treatment class of recommendation III, level of evidence B [10]. These limitations preclude pre-hospital use of prasugrel in NSTE-ACS patients. In contrast, a ticagrelor loading dose of $180 \mathrm{mg}$ followed by $90 \mathrm{mg}$ b.i.d. is recommended in all patients with moderate-to-high risk of ischemic events, regardless of the initial management strategy, unless contraindicated. It is important to note that this recommendation also includes patients who had received clopidogrel previously, in this case clopidogrel should be discontinued at the time of initiation of ticagrelor treatment.

\section{Conclusions}

The ESC guidelines recommend the use of ticagrelor or prasugrel as preferred P2Y12 receptor inhibitors in all ACS patients, unless contraindicated, e.g. due to an excessive risk of bleeding $[2,3]$. Contrary to prasugrel, ticagrelor is recommended for all patients with STEMI and moderate-to-high risk NSTE-ACS, regardless of the management strategy, including patients designated to conservative treatment and those pre-treated with clopidogrel. Use of clopidogrel in patients with STEMI or NSTE-ACS should be limited to situations when both ticagrelor and prasugrel are unavailable or contraindicated - class of recommendation $\mathrm{I}$, level of evidence $\mathrm{B}[2,3]$. The choice of the optimal time to start the therapy with oral antiplatelet drugs is not well supported by results of the available clinical studies. Hence, it is difficult to formulate universal recommendations concerning early administration of DAPT. However, in very high-risk patients who require urgent invasive diagnostics and most commonly also PCI, it seems advisable to institute DAPT as soon as possible $[55,56]$. A reasonable approach is to begin the treatment with a P2Y12 receptor inhibitor based on the administration timing tested for the drug in the approval studies (i.e. as soon as possible and deemed safe for clopidogrel and ticagrelor, or after the indication for PCI is established based on coronary anatomy for prasugrel in NSTE-ACS) [3, 57-59]. In ACS patients treated with $\mathrm{CABG}$, therapy with ticagrelor is preferred due to favourable results in reduction of risk of adverse cardiovascular events, including death rates, as compared with clopidogrel, without increasing the risk of severe CABG-related bleeding [55]. Therefore, when initiating antiplatelet therapy in the pre-hospital setting, it seems justified to prefer ticagrelor as the drug of first choice in patients who may potentially require urgent cardiac surgery [1].

It should also be noted that, in accordance with the Directive of the Minister of Health dated 20 April 2016, paramedics and emergency medical team members are allowed to (after ECG teletransmission and consultation with the physician evaluating the ECG) administer some P2Y12 inhibitors, namely clopidogrel and ticagrelor, but not prasugrel. In the periprocedural period ACS patients require antithrombotic treatment apart from DAPT, and according to the above-mentioned Directive of the Minister of Health, unfractionated heparin $(70-100 \mathrm{U} / \mathrm{kg})$ is the only antithrombotic agent that can be administered by paramedics and emergency medical team members [56].

In the pre-hospital period patients with ACS may experience vomiting with risk of loss of yet unabsorbed antiplatelet drugs. In such cases the time elapsed from drug intake to vomiting and the potential presence of tablets in the vomited content should be documented. The decision on administration of an additional dose of antiplatelet drugs should be left to the discretion of the physician at the destination hospital.

Importantly, despite several novelties included in the 2017 ESC guidelines for the management of STEMI and 2017 focused update on DAPT, general recommendations for the pre-hospital management of patients with ACS remain unaltered, especially concerning suggested antiplatelet therapy.

\section{Summary}

1. Use of ECG tele-transmission and teleconsultation systems should be a part of standard management in all patients with suspected ACS.

2. In order to make the therapeutic management of STEMI patients uniform, after preliminary diagnosis and teleconsultation with a cardiologist, if no contraindications exist, DAPT should be initiated (ASA $300 \mathrm{mg}$; ticagrelor $180 \mathrm{mg}$ ) (Fig. 2).

3. Routine pre-hospital initiation of DAPT (ASA $300 \mathrm{mg}$; ticagrelor $180 \mathrm{mg}$ ) is advisable in very high risk NSTE-ACS patients, in whom the preliminary assessment indicates the need for urgent invasive treatment. 


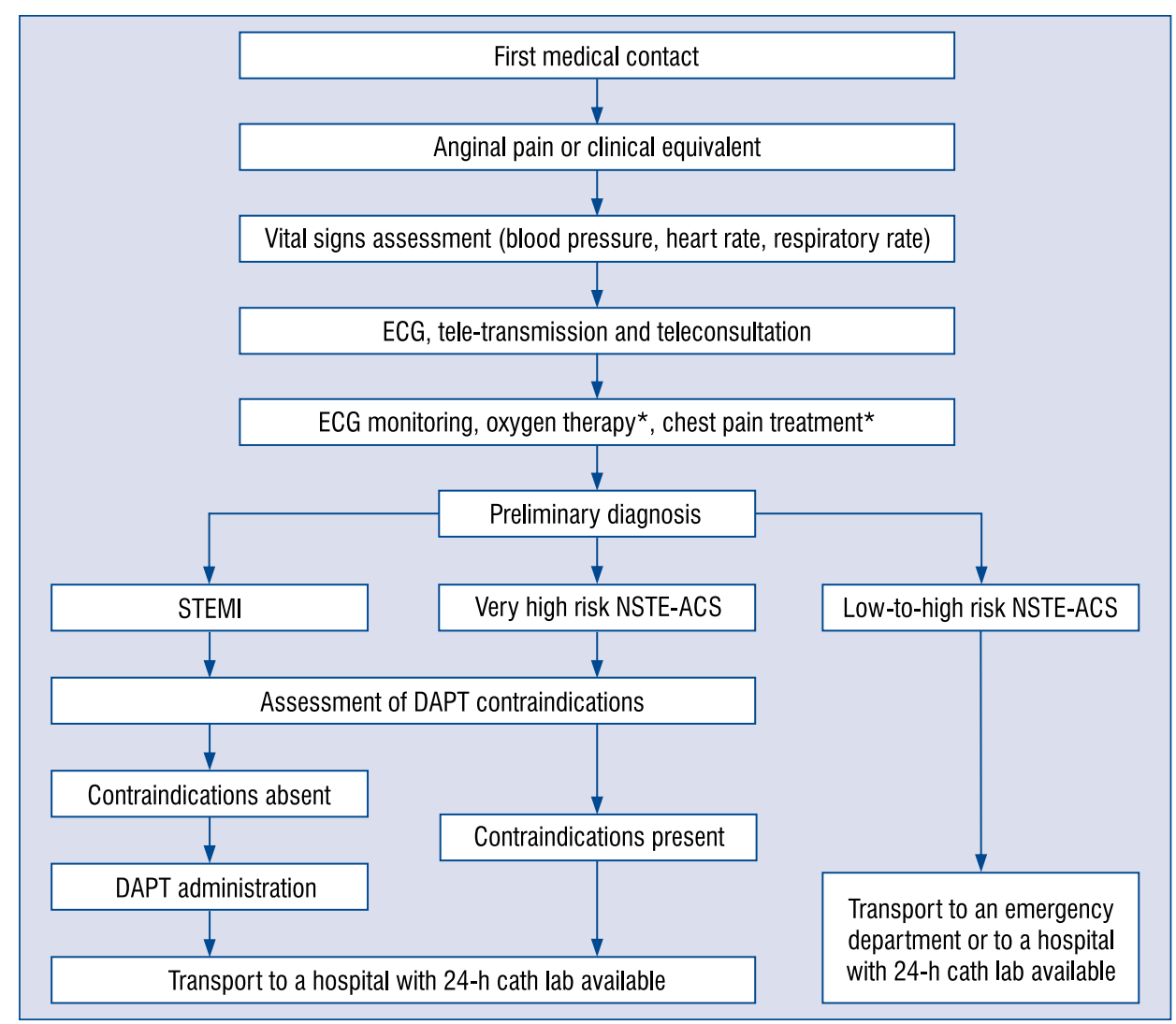

Figure 2. Algorithm for pre-hospital management of patients with acute coronary syndromes (modified and adopted from [1]); DAPT — dual antiplatelet therapy (preferred treatment: acetylsalicylic acid + ticagrelor); ECG — electrocardiography; NSTE-ACS - non-ST-segment elevation acute coronary syndrome; STEMI — ST-segment elevation myocardial infarction; *If required.

4. Considering the lack of consistent data, analgesic treatment applied in patients with ACS during their transfer to hospital should be chosen and adjusted on an individual basis. Use of non-opioid drugs is not recommended in such conditions due to increased risk of bleeding when used simultaneously with DAPT. Due to interactions with oral antiplatelet drugs, care must be taken when morphine or perhaps when other opioids are used.

Conflict of interest: Jacek Kubica: fee for lectures and involvement in AstraZeneca advisory board; Piotr Adamski: fee for lectures for AstraZeneca; Przemysław Paciorek: none; Jerzy R. Ładny: fee for lectures for AstraZeneca; Zbigniew Kalarus: fee for lectures for Eli Lilly and for involvement in AstraZeneca advisory board; Waldemar Banasiak: fee for lectures for AstraZeneca and Bayer, fee for involvement in AstraZeneca, Bayer, and Eli Lilly advisory boards; Wacław Kochman: none; Jarosław Gorący: fee for lectures for AstraZeneca;
Beata Wożakowska-Kapłon: fee for lectures and for involvement in AstraZeneca, Adamed, KRKA, and Sano advisory boards; Eliano Pio Navarese: none; Andrzej Kleinrok: none; Robert Gil: none; Maciej Lesiak: fee for lectures for AstraZeneca; Jarosław Drożdż: fee for lectures and involvement in Polpharma advisory board; Aldona Kubica: none; Krzysztof J. Filipiak: fee for lectures and for involvement in AstraZeneca, Adamed, KRKA, Polpharma, and Sano advisory boards; Jarosław Kaźmierczak: fee for involvement in AstraZeneca advisory board; Aleksander Goch: none; Stefan Grajek: fee for involvement in AstraZeneca advisory board; Andrzej Basiński: none; Łukasz Szarpak: none; Grzegorz Grześk: none; Piotr Hoffman: none; Wojciech Wojakowski: fee for lectures for AstraZeneca; Zbigniew Gąsior: fee for lectures for Servier, and Actelion; Sławomir Dobrzycki: none; Jolanta M. Siller-Matula: fee for lectures and involvement in AstraZeneca, Daiichi Sankyo, and Eli Lilly advisory boards; Adam Witkowski: none; Wiktor Kuliczkowski: none; Marcin Gruchała: none; Dariusz Timler: none; Grzegorz 
Opolski: none; Dariusz Dudek: fee for lectures and involvement in AstraZeneca advisory board; Jacek Legutko: fee for lectures and involvement in AstraZeneca advisory board; Marzenna Zielińska: fee for lectures for AstraZeneca; Jarosław Wójcik: none.

\section{References}

1. Kubica J, Adamski P, Paciorek P, et al. Anti-aggregation therapy in patients with acute coronary syndrome - recommendations for medical emergency teams. Experts' standpoint. Kardiol Pol. 2017; 75(4): 399-408, doi: 10.5603/KP.a2017.0057, indexed in Pubmed: 28421594.

2. Ibanez B, James S, Agewall S, et al. 2017 ESC Guidelines for the management of acute myocardial infarction in patients presenting with ST-segment elevation: The Task Force for the management of acute myocardial infarction in patients presenting with ST-segment elevation of the European Society of Cardiology (ESC). Eur Heart J. 2018; 39(2): 119-177, doi: 10.1093/eurheartj/ ehx393, indexed in Pubmed: 28886621.

3. Valgimigli M, Bueno H, Byrne RA, et al. 2017 ESC focused update on dual antiplatelet therapy in coronary artery disease developed in collaboration with EACTS: The Task Force for dual antiplatelet therapy in coronary artery disease of the European Society of Cardiology (ESC) and of the European Association for Cardio-Thoracic Surgery (EACTS). Eur Heart J. 2018; 39(3): 213-260, doi: 10.1093/eurheartj/ehx419, indexed in Pubmed: 28886622.

4. Gierlotka M, Zdrojewski T, Wojtyniak B, et al. Incidence, treatment, in-hospital mortality and one-year outcomes of acute myocardial infarction in Poland in 2009-2012: nationwide AMIPL database. Kardiol Pol. 2015; 73(3): 142-158, doi: 10.5603/ KP.a2014.0213, indexed in Pubmed: 25371307.

5. Terkelsen CJ, Sørensen JT, Maeng M, et al. System delay and mortality among patients with STEMI treated with primary percutaneous coronary intervention. JAMA. 2010; 304(7): 763-771, doi: 10.1001/jama.2010.1139, indexed in Pubmed: 20716739.

6. Huber K, De Caterina R, Kristensen SD, et al. Pre-hospital reperfusion therapy: a strategy to improve therapeutic outcome in patients with ST-elevation myocardial infarction. Eur Heart J. 2005; 26(19): 2063-2074, doi: 10.1093/eurheartj/ehi413, indexed in Pubmed: 16055497.

7. Lopes RD, Siha H, Fu Y, et al. Diagnosing acute myocardial infarction in patients with left bundle branch block. Am J Cardiol. 2011; 108(6): 782-788, doi:10.1016/j.amjcard.2011.05.006, indexed in Pubmed: 21726838.

8. Chan AW, Kornder J, Elliott H, et al. Improved survival associated with pre-hospital triage strategy in a large regional ST-segment elevation myocardial infarction program. JACC Cardiovasc Interv. 2012; 5(12): 1239-1246, doi: 10.1016/j.jcin.2012.07.013, indexed in Pubmed: 23257372.

9. Widimsky P, Rohác F, Stásek J, et al. Primary angioplasty in acute myocardial infarction with right bundle branch block: should new onset right bundle branch block be added to future guidelines as an indication for reperfusion therapy? Eur Heart J. 2012; 33(1): 86-95, doi: 10.1093/eurheartj/ehr291, indexed in Pubmed: 21890488.

10. Roffi M, Patrono C, Collet JP, et al. 2015 ESC Guidelines for the management of acute coronary syndromes in patients presenting without persistent ST-segment elevation: Task Force for the
Management of Acute Coronary Syndromes in Patients Presenting without Persistent ST-Segment Elevation of the European Society of Cardiology (ESC). Eur Heart J. 2016; 37(3): 267-315, doi: 10.1093/eurheartj/ehv320, indexed in Pubmed: 26320110.

11. Dhruva VN, Abdelhadi SI, Anis A, et al. ST-Segment Analysis Using Wireless Technology in Acute Myocardial Infarction (STAT-MI) trial. J Am Coll Cardiol. 2007; 50(6): 509-513, doi: 10.1016/j.jacc.2007.04.049, indexed in Pubmed: 17678733.

12. Fordyce CB, Al-Khalidi HR, Jollis JG, et al. Association of Rapid Care Process Implementation on Reperfusion Times Across Multiple ST-Segment-Elevation Myocardial Infarction Networks. Circ Cardiovasc Interv. 2017; 10(1), doi: 10.1161/CIRCINTERVENTIONS.116.004061, indexed in Pubmed: 28082714.

13. Stowens JC, Sonnad SS, Rosenbaum RA. Using EMS Dispatch to Trigger STEMI Alerts Decreases Door-to-Balloon Times. West J Emerg Med. 2015; 16(3): 472-480, doi: 10.5811/westjem.2015.4.24248, indexed in Pubmed: 25987932.

14. Squire BT, Tamayo-Sarver JH, Rashi P, et al. Effect of prehospital cardiac catheterization lab activation on door-to-balloon time, mortality, and false-positive activation. Prehosp Emerg Care. 2014; 18(1): 1-8, doi: 10.3109/10903127.2013.836263, indexed in Pubmed: 24329031.

15. Nallamothu BK, Normand SLT, Wang Y, et al. Relation between door-to-balloon times and mortality after primary percutaneous coronary intervention over time: a retrospective study. Lancet. 2015; 385(9973): 1114-1122, doi: 10.1016/S0140-6736(14)61932-2, indexed in Pubmed: 25467573.

16. Bagai A, Jollis JG, Dauerman HL, et al. Emergency department bypass for ST-Segment-elevation myocardial infarction patients identified with a prehospital electrocardiogram: a report from the American Heart Association Mission: Lifeline program. Circulation. 2013; 128(4): 352-359, doi:10.1161/CIRCULATIONAHA.113.002339, indexed in Pubmed: 23788525.

17. Welsh RC, Chang W, Goldstein P, et al. Time to treatment and the impact of a physician on prehospital management of acute ST elevation myocardial infarction: insights from the ASSENT-3 PLUS trial. Heart. 2005; 91(11): 1400-1406, doi: 10.1136/ hrt.2004.054510, indexed in Pubmed: 15774607.

18. Parodi G. Editor's Choice-Chest pain relief in patients with acute myocardial infarction. Eur Heart J Acute Cardiovasc Care. 2016; 5(3): 277-281, doi:10.1177/2048872615584078, indexed in Pubmed: 25904757.

19. Kubica J, Kubica A, Jilma B, et al. Impact of morphine on antiplatelet effects of oral P2Y12 receptor inhibitors. Int J Cardiol. 2016; 215: 201-208, doi:10.1016/j.ijcard.2016.04.077, indexed in Pubmed: 27128531.

20. Kubica J, Adamski P, Ostrowska M, et al. Morphine delays and attenuates ticagrelor exposure and action in patients with myocardial infarction: the randomized, double-blind, placebo-controlled IMPRESSION trial. Eur Heart J. 2016; 37(3): 245-252, doi: 10.1093/eurheartj/ehv547.

21. Hobl EL, Stimpfl T, Ebner J, et al. Morphine decreases clopidogrel concentrations and effects: a randomized, double-blind, placebo-controlled trial. J Am Coll Cardiol. 2014; 63(7): 630-635, doi: 10.1016/j.jacc.2013.10.068, indexed in Pubmed: 24315907.

22. Parodi G, Bellandi B, Xanthopoulou I, et al. Morphine is associated with a delayed activity of oral antiplatelet agents in patients with ST-elevation acute myocardial infarction undergoing primary percutaneous coronary intervention. Circ Cardiovasc Interv. 2015; 8(1), doi: 10.1161/CIRCINTERVENTIONS.114.001593, indexed in Pubmed: 25552565. 
23. Kubica J, Adamski P, Ostrowska M, et al. Influence of morphine on pharmacokinetics and pharmacodynamics of ticagrelor in patients with acute myocardial infarction (IMPRESSION): study protocol for a randomized controlled trial. Trials. 2015; 16: 198, doi: 10.1186/s13063-015-0724-z, indexed in Pubmed: 25925591.

24. Puymirat E, Lamhaut L, Bonnet N, et al. Correlates of pre-hospital morphine use in ST-elevation myocardial infarction patients and its association with in-hospital outcomes and long-term mortality: the FAST-MI (French Registry of Acute ST-elevation and non-ST-elevation Myocardial Infarction) programme. Eur Heart J. 2016; 37(13): 1063-1071, doi: 10.1093/eurheartj/ehv567, indexed in Pubmed: 26578201.

25. Meine TJ, Roe MT, Chen AY, et al. Association of intravenous morphine use and outcomes in acute coronary syndromes: results from the CRUSADE Quality Improvement Initiative. Am Heart J. 2005; 149(6): 1043-1049, doi: 10.1016/j.ahj.2005.02.010, indexed in Pubmed: 15976786.

26. Iakobishvili Z, Porter A, Battler A, et al. Effect of narcotic treatment on outcomes of acute coronary syndromes. Am J Cardiol. 2010; 105(7): 912-916, doi: 10.1016/j.amjcard.2009.11.027, indexed in Pubmed: 20346305.

27. de Waha S, Eitel I, Desch S, et al. Intravenous morphine administration and reperfusion success in ST-elevation myocardial infarction: insights from cardiac magnetic resonance imaging. Clin Res Cardiol. 2015; 104(9): 727-734, doi: 10.1007/s00392015-0835-2, indexed in Pubmed: 25725777.

28. Steg PhG, James SK, Atar D, et al. ESC Guidelines for the management of acute myocardial infarction in patients presenting with ST-segment elevation. Eur Heart J. 2012; 33(20): 2569-2619, doi: 10.1093/eurheartj/ehs215, indexed in Pubmed: 22922416

29. Alexopoulos D, Barampoutis N, Gkizas V, et al. Crushed versus integral tablets of ticagrelor in ST-segment elevation myocardial infarction patients: a randomized pharmacokinetic/pharmacodynamic study. Clin Pharmacokinet. 2016; 55(3): 359-367, doi: 10.1007/s40262-015-0320-0, indexed in Pubmed: 26315810.

30. Parodi G, Xanthopoulou I, Bellandi B, et al. Ticagrelor crushed tablets administration in STEMI patients: the MOJITO study. J Am Coll Cardiol. 2015; 65(5): 511-512, doi: 10.1016/j. jacc.2014.08.056, indexed in Pubmed: 25660931.

31. Rollini F, Franchi F, Angiolillo DJ, et al. Crushed Prasugrel Tablets in Patients With STEMI Undergoing Primary Percutaneous Coronary Intervention: The CRUSH Study. J Am Coll Cardiol. 2016; 67(17): 1994-2004, doi: 10.1016/j.jacc.2016.02.045, indexed in Pubmed: 27012781.

32. Niezgoda P, Sikora J, Barańska M, et al. Crushed sublingual versus oral ticagrelor administration strategies in patients with unstable angina. A pharmacokinetic/pharmacodynamic study. Thromb Haemost. 2017; 117(4): 718-726, doi: 10.1160/TH1608-0670, indexed in Pubmed: 28203684.

33. Stub D, Smith K, Bernard S, et al. AVOID Investigators. Air Versus Oxygen in ST-Segment-Elevation Myocardial Infarction. Circulation. 2015; 131(24): 2143-2150, doi: 10.1161/CIRCULATIONAHA.114.014494, indexed in Pubmed: 26002889.

34. Thygesen K, Alpert J, Jaffe A, et al. Third universal definition of myocardial infarction. Eur Heart J. 2012; 33(20): 2551-2567, doi:10.1093/eurheartj/ehs184.

35. Lange RA, Hillis LD. Antiplatelet therapy for ischemic heart disease. N Engl J Med. 2004; 350(3): 277-280, doi: 10.1056/ NEJMe038191, indexed in Pubmed: 14724308.
36. Windecker S, Kolh P, Alfonso F, et al. 2014 ESC/EACTS Guidelines on myocardial revascularization: The Task Force on Myocardial Revascularization of the European Society of Cardiology (ESC) and the European Association for Cardio-Thoracic Surgery (EACTS)Developed with the special contribution of the European Association of Percutaneous Cardiovascular Interventions (EAPCI). Eur Heart J. 2014; 35(37): 2541-2619, doi: 10.1093/ eurheartj/ehu278, indexed in Pubmed: 25173339.

37. Sheyin O, Perez X, Pierre-Louis B, et al. The optimal duration of dual antiplatelet therapy in patients receiving percutaneous coronary intervention with drug-eluting stents. Cardiol J. 2016; 23(3): 307-316, doi: 10.5603/CJ.a2015.0078, indexed in Pubmed: 26711462.

38. Kubica A, Kasprzak M, Siller-Matula J, et al. Time-related changes in determinants of antiplatelet effect of clopidogrel in patients after myocardial infarction. Eur J Pharmacol. 2014; 742: 47-54, doi: 10.1016/j.ejphar.2014.08.009, indexed in Pubmed: 25199965.

39. Serebruany VL, Midei MG, Meilman H, et al. Platelet inhibition with prasugrel (CS-747) compared with clopidogrel in patients undergoing coronary stenting: the subset from the JUMBO study. Postgrad Med J. 2006; 82(968): 404-410, doi: 10.1136/ pgmj.2006.047696, indexed in Pubmed: 16754711.

40. Wiviott SD, Trenk D, Frelinger AL, et al. PRINCIPLE-TIMI 44 Investigators. Prasugrel compared with high loading- and maintenance-dose clopidogrel in patients with planned percutaneous coronary intervention: the Prasugrel in Comparison to Clopidogrel for Inhibition of Platelet Activation and Aggregation-Thrombolysis in Myocardial Infarction 44 trial. Circulation. 2007; 116(25): 2923-2932, doi: 10.1161/CIRCULATIONAHA.107.740324, indexed in Pubmed: 18056526.

41. Husted SE, Storey RF, Bliden K, et al. Pharmacokinetics and pharmacodynamics of ticagrelor in patients with stable coronary artery disease: results from the ONSET-OFFSET and RESPOND studies. Clin Pharmacokinet. 2012; 51(6): 397-409, doi: 10.2165/11599830-000000000-00000, indexed in Pubmed: 22515556.

42. Steg PG, James S, Harrington RA, et al. Inhibition of platelet aggregation by AZD6140, a reversible oral P2Y12 receptor antagonist, compared with clopidogrel in patients with acute coronary syndromes. J Am Coll Cardiol. 2007; 50(19): 1852-1856, doi: 10.1016/j.jacc.2007.07.058, indexed in Pubmed: 17980251.

43. Mehta SR, Tanguay JF, Eikelboom JW, et al. Double-dose versus standard-dose clopidogrel and high-dose versus low-dose aspirin in individuals undergoing percutaneous coronary intervention for acute coronary syndromes (CURRENT-OASIS 7): a randomised factorial trial. Lancet. 2010; 376(9748): 1233-1243, doi: 10.1016/ S0140-6736(10)61088-4, indexed in Pubmed: 20817281.

44. Dans AL, Connolly SJ, Wallentin L, et al. Concomitant use of antiplatelet therapy with dabigatran or warfarin in the Randomized Evaluation of Long-Term Anticoagulation Therapy (RE-LY) trial. Circulation. 2013; 127(5): 634-640, doi: 10.1161/CIRCULATIONAHA.112.115386, indexed in Pubmed: 23271794.

45. Sørensen R, Hansen ML, Abildstrom SZ, et al. Risk of bleeding in patients with acute myocardial infarction treated with different combinations of aspirin, clopidogrel, and vitamin $\mathrm{K}$ antagonists in Denmark: a retrospective analysis of nationwide registry data. Lancet. 2009; 374(9706): 1967-1974, doi:10.1016/ S0140-6736(09)61751-7, indexed in Pubmed: 20006130.

46. Hansen ML, Sørensen R, Clausen MT, et al. Risk of bleeding with single, dual, or triple therapy with warfarin, aspirin, and clopidogrel in patients with atrial fibrillation. Arch Intern Med. 
2010; 170(16): 1433-1441, doi: 10.1001/archinternmed.2010.271, indexed in Pubmed: 20837828.

47. Oldgren J, Budaj A, Granger CB, et al. RE-DEEM Investigators. Dabigatran vs. placebo in patients with acute coronary syndromes on dual antiplatelet therapy: a randomized, double-blind, phase II trial. Eur Heart J. 2011; 32(22): 2781-2789, doi: 10.1093/ eurheartj/ehr113, indexed in Pubmed: 21551462.

48. Kubica J, Kozinski M, Navarese EP, et al. Cangrelor: an emerging therapeutic option for patients with coronary artery disease. Curr Med Res Opin. 2014; 30(5): 813-828, doi: 10.1185/030079 95.2014.880050, indexed in Pubmed: 24393016.

49. Bhatt D, Stone G, Mahaffey K, et al. Effect of Platelet Inhibition with Cangrelor during PCI on Ischemic Events. N Engl J Med. 2013; 368(14): 1303-1313, doi: 10.1056/nejmoa1300815.

50. Kubica J, Pstragowski K, Adamski P, et al. Mild therapeutic hypothermia for patients with acute coronary syndrome and cardiac arrest treated with percutaneous coronary intervention (UNICORN). The design and rationale for the prospective, observational, multicenter study. Med Res J. 2016; 1(1): 23-27, doi: 10.5603/mrj.2016.0004.

51. Klimczuk T, Kubica J, Kasprzak M, et al. Łagodna hipotermia terapeutyczna po nagłym zatrzymaniu krążenia w przebiegu ostrego zespołu wieńcowego - doświadczenia $\mathrm{z}$ wdrażania metody. Folia Cardiol. 2015; 10(1): 19-24, doi: 10.5603/fc.2015.0005.

52. Wiviott SD, Braunwald E, McCabe CH, et al. Prasugrel versus clopidogrel in patients with acute coronary syndromes. N Engl J Med. 2007; 357(20): 2001-2015, doi: 10.1056/NEJMoa0706482, indexed in Pubmed: 17982182.

53. Wallentin L, Becker RC, Budaj A, et al. Ticagrelor versus clopidogrel in patients with acute coronary syndromes. N Engl J Med. 2009; 361(11): 1045-1057, doi: 10.1056/NEJMoa0904327, indexed in Pubmed: 19717846.

54. Adamski P, Adamska U, Ostrowska M, et al. New directions for pharmacotherapy in the treatment of acute coronary syn- drome. Expert Opin Pharmacother. 2016; 17(17): 2291-2306, doi: 10.1080/14656566.2016.1241234, indexed in Pubmed: 27677394.

55. Held C, Asenblad N, Bassand JP, et al. Ticagrelor versus clopidogrel in patients with acute coronary syndromes undergoing coronary artery bypass surgery: results from the PLATO (Platelet Inhibition and Patient Outcomes) trial. J Am Coll Cardiol. 2011; 57(6): 672-684, doi: 10.1016/j.jacc.2010.10.029, indexed in Pubmed: 21194870.

56. Directive of the Minister of Health dated 20 April 2016 on medical rescue procedures and health services different than medical rescue procedures, which can be performed by paramedic.

57. Kleinrok A, Płaczkiewicz DT, Puźniak M, et al. Electrocardiogram teletransmission and teleconsultation: essential elements of the organisation of medical care for patients with ST segment elevation myocardial infarction: a single centre experience. Kardiol Pol. 2014; 72(4): 345-354, doi: 10.5603/KP.a2013.0352, indexed in Pubmed: 24408066.

58. Abraham NS, Hlatky MA, Antman EM, et al. ACCF/ACG/AHA 2010 expert consensus document on the concomitant use of proton pump inhibitors and thienopyridines: a focused update of the ACCF/ACG/AHA 2008 expert consensus document on reducing the gastrointestinal risks of antiplatelet therapy and NSAID use. A Report of the American College of Cardiology Foundation Task Force on Expert Consensus Documents. J Am Coll Cardiol. 2010; 56(24): 2051-2066, doi: 10.1016/j.jacc.2010.09.010, indexed in Pubmed: 21126648.

59. Rakowski T, Siudak Z, Dziewierz A, et al. Contemporary use of P2Y12 inhibitors in patients with ST-segment elevation myocardial infarction referred to primary percutaneous coronary interventions in Poland: Data from ORPKI national registry. J Thromb Thrombolysis. 2018; 45(1): 151-157, doi: 10.1007/s11239-0171579-9, indexed in Pubmed: 29075924. 